\title{
The Effects of Sexual Dimorphism, Asymmetry, and Inter- trait Association on the Distribution of Thirteen Deciduous Dental Nonmetric Traits in a Sample of Pima Amerindians
}

\author{
Matthew W. Tocheri \\ Department of Anthropology, Arizona State University, Tempe AZ 85287-2402
}

\begin{abstract}
One hundred dental casts of modern Pima Amerindian children, 50 male and 50 female, were examined for the presence and expression of thirteen deciduous nonmetric traits. The effects of sexual dimorphism, asymmetry, and inter-trait association on trait presence were examined to evaluate their utility in population distance studies. No statistically significant differences between the sexes were observed. The majority of examined variants displayed a strong trend toward bilateral expression and no statistically significant differences between antimeres occurred. These data support the hypothesis that strong genetic components coupled with negligible environmental influences are involved in deciduous trait presence. Five statistically significant associations between variants were detected. Four of these involved a combination of incisor and canine shoveling within and between jaws. This indicates that their combined use in biological distance studies violates the mathematical assumption of independence. The lack of significant sexual dimorphism and asymmetry in the deciduous discrete traits examined herein supports their use in population distance analyses if precautions are taken to use non-associated traits.
\end{abstract}

The number of studies dealing with nonmetric variation in human deciduous teeth pale in comparison with those of the permanent dentition (Scott and Turner, 1997). This discrepancy has been attributed to the paucity of deciduous dental remains at archaeological sites (Kitagawa, 2000; Sciulli, 1998), their shorter functional life span in comparison with permanent teeth (Kitagawa, 2000), and the difficulty in obtaining a set of Hanihara's (1961) reference plaques (Mayhall, 1992). Several studies, however, indicate that deciduous nonmetric dental traits are useful tools in assessing the biological relationships of human populations (Goldstein, 1948; Grine, 1986, 1990; Hanihara, 1956, 1961, 1963, 1965, 1970; Hrdlicka, 1920; Johnse, 1947; Jorgensen, 1956; Lukacs and Walimbe, 1984; Sciulli, 1977, 1990, 1998; Smith, 1976, 1978).

A number of fundamental assumptions underpin the use of discrete dental traits in population analyses. These include the following:

1. genes strongly control trait presence and expression

2. environmental influences on trait presence and expression are negligible

3. the effects of sexual dimorphism on trait presence and expression are minimal

4. antimere asymmetry is the result of environmental rather than genetic influences

5. associations between traits are not biologically meaningful

Editor's note: Mr. Tocheri's paper was awarded First Prize for 2001 in the Albert A. Dahlberg student research competition sponsored by the Dental Anthropology Association.
This paper tests the validity of the latter three assumptions as they relate to deciduous dental morphology. In turn, this sheds light on the first two assumptions. Establishing the utility of deciduous nonmetric traits in human population research is imperative if they are to be used successfully in biological distance analyses. While skeletal samples typically do not consist of a preponderance of juveniles, this is not

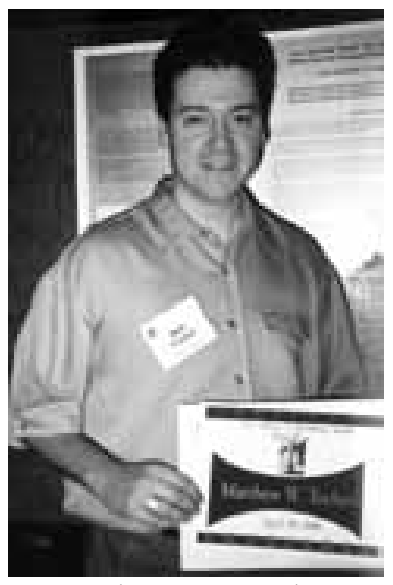

Matthew W. Tocheri always the case (Fairgrieve and Molto, 2000; Tocheri and Molto, in press). Therefore, deciduous nonmetric dental traits offer a valuable alternative source of biological data.

In this study, my first objective is to examine the effects of sexual dimorphism on deciduous trait presence and expression. Discrete dental traits rarely exhibit sexual dimorphism in the permanent teeth and when they do, it is primarily restricted to a few variants (Harris, 1980; Nichol, 1990; Scott, 1977; Turner et al., 1991). Theoretically, deciduous traits may be influenced by sex more than permanent traits since all deciduous teeth begin to form in utero. The presence of dihydrotestosterone and other androgens in male embryos act to differentiate them from females beginning around the seventh fetal week (Daly and Wilson, 1983; Mange and Mange, 1990). Dempsey et al. (1999) studied the permanent teeth of a large sample of twins and singletons $(n=448)$ and found that females 
which had a male twin "have consistently larger teeth (on average) than other females" (Dempsey et al., 1999: 577). They proposed that these differences were the result of "diffusion of sex hormones from male to female co-twins in utero" (Dempsey et al., 1999:577). How these naturally occurring steroids affect the development and expression of primary nonmetric variants is not well understood because few studies have examined sexual dimorphism in these traits. Hanihara $(1965,1970)$ reported that "no differences between sexes has been found" for several deciduous variants; however, he did not discuss any statistical methodology (Hanihara, 1965: 136, 1970). Grine (1990) examined a sample of Kalahari San children and found a lack of statistically significant sexual dimorphism in the deciduous traits he scored. Similarly, he found no sex differences in a sample of South African black children (Grine, 1986). Sex differences, however, may vary between populations in both dental (Harris, 1980) and skeletal traits (Ossenberg, 1976; Molto, 1985). Therefore, it is important to document the effects of sex on deciduous trait presence and expression in other human groups.

My second objective is to examine asymmetry in trait presence and expression on the anitmeres. Asymmetrical studies can reveal information pertaining to the environmental and functional influences on the presence of dental and skeletal discrete traits along with their underlying genotype (Mayhall and Saunders, 1986; Turner, 1985; Trinkaus, 1978). Several researchers have examined asymmetry in permanent (Bailey-Schmidt, 1995; Baume and Crawford, 1980; Biggerstaff, 1972; Harris, 1977; Meredith and Hixon, 1954; Nichol, 1990) and in primary dental traits (Townsend, 1981; Townsend and Brown, 1980, 1981) and have found it to be a random phenomenon influenced by the environment. A sample size greater than 100 is typically considered appropriate for statistical analyses of asymmetry (Garn et al., 1979; Smith et al., 1982), however, the documentation of observed trends in smaller samples can aid future research.

Understanding the associations among deciduous dental traits is necessary to increase their effectiveness in biological distance calculations. Associations between cranial nonmetric variables have been shown to adversely affect the calculation of C.A.B. Smith's Mean Measure of Divergence (MMD) (Molto, 1985). Similar results have been reported for distance analyses using permanent discrete traits (Hawkey, personal communication 2000; Nichol, 1990). Therefore, my final objective is to statistically examine the associations between these thirteen traits and critically evaluate their combined use in population distance studies.

\section{MATERIALS AND METHODS}

The sample consisted of 100 deciduous dental casts, 50 male and 50 female, of Pima Amerindians from southern Arizona. All casts were collected from living children by Albert A. and Thelma Dahlberg between 1949 and 1975 and are curated at the Dental Anthropology Laboratory at Arizona State University. The age and sex of each individual was recorded at the time of casting. The majority of casts examined in this study represent individuals between 5 and 10 years of age. Approximately $60 \%$ of their deciduous teeth were present for analysis.

Thirteen nonmetric traits were scored following the plaques (D series) and written descriptions of Hanihara (1961). Only teeth unaffected by wear or pathology were scored. A list of the examined traits and a description of how grades were dichotomized into present-absent categories is presented in Table 1. Hanihara's (1961) dichotomizing criteria were used for all traits. Throughout the text and tables the following abbreviations are used: 1 , lower; $u$, upper; i, incisor; c, canine; $\mathrm{m}$, molar; 1 , first in tooth series; 2 , second in tooth series.

Twenty dentitions were randomly selected and re-scored on separate occasions. In order to analyze intra-observer reliability, an integral part of any discrete trait study (Molto, 1979; Nichol and Turner, 1986). Intra-observer reliability scores are reported by grade, presence/absence per tooth and presence/absence per individual in Table 2. Scoring consistency was lowest by grade $(75 \%)$ and highest per individual $(92 \%)$. I considered the observed scoring consistency by grade to be too low to analyze differences between degrees of expression. Therefore, only differences between trait presence and absence are reported herein. Per individual, seven out of 13 traits were scored reliably $100 \%$ of the time, two between $90-95 \%$, and three between $80-85 \%$. The Protostylid ( $(\mathrm{lm} 2)$ was the least reliably scored trait (65\% per individual).

The relative frequencies of each trait were calculated using the individual-count method. This assumes each trait is symmetrical and predominantly controlled by a single genotype; therefore, the strongest expression of the trait in an individual represents that genotype most accurately (Scott, 1980; Turner and Scott, 1977; Turner, 1985; Turner et al., 1991).

Differences in trait relative frequency between males and females and also between the right and left sides were analyzed. The Pearson chi-square test statistic was used to detect significance $(p<0.05)$. Inter-trait associations were measured using the phi coefficient with $\mathrm{p}$ values less than 0.01 considered significant following the recommendations of Molto (1985) and Sjøvold (1973). In all statistical analyses, if one or more cells had an expected count less than 5, Fisher's exact test was used to examine significance.

Asymmetry was investigated using the index of bilaterality (BI), calculated by dividing the frequency of bilateral presence by the sum of the frequencies of unilateral and bilateral presence, and multiplying by 100 (Molto, 1983). This index reveals the symmetrical 
TABLE 1. The trait list and scoring procedure used in this study

\begin{tabular}{lllc}
\hline Tooth & Trait & Grades Scored & Presence $^{1}$ \\
\hline ui1 & Shovel & $0,1,2,3$ & 2,3 \\
ui2 & Shovel & $0,1,2,3$ & 2,3 \\
uc & Shovel & $0,1,2,3$ & 2,3 \\
um1 & Crown Pattern & $2,3 \mathrm{H} 1,3 \mathrm{H} 2,3 \mathrm{M} 1,3 \mathrm{M} 2,4-, 4$ & $4-, 4$ \\
um2 & Crown Pattern & $3+\mathrm{A}, 3+\mathrm{B}, 4-, 4$ & $4-, 4$ \\
um2 & Carabelli's Cusp & $0,1,2,3,4,5,6,7$ & $4-7$ \\
$\operatorname{li} 1$ & Shovel & $0,1,2,3$ & 2,3 \\
$\operatorname{li} 2$ & Shovel & $0,1,2,3$ & 2,3 \\
$\operatorname{lc}$ & Shovel & $0,1,2,3$ & 2,3 \\
$\operatorname{lm} 2$ & Protostylid & $0,1,2,3,4,5,6$ & $2-6$ \\
$\operatorname{lm} 2$ & Cusp 7 & $0,1,2,3$ & $1-3$ \\
$\operatorname{lm} 2$ & Central Ridge & 0,1 & 1 \\
$\operatorname{lm} 2$ & Distal Trigonid Crest & $0,1,2$ & 1,2 \\
\hline
\end{tabular}

${ }^{1}$ follows Hanihara's (1961) dichotomy

tendencies of a trait when it is present. In other words, individuals who exhibit bilateral absence of a trait are not included in the calculation of the index. An index value greater than 50 indicates the trait occurs more often bilaterally whereas a value less than 50 indicates it occurs more often unilaterally.

\section{RESULTS}

The relative frequencies of each trait by sex and by antimere are shown in Tables 3 and 4, respectively. No statistically significant difference between the sexes or between antimeres was observed $(p<0.05)$. All traits displayed a tendency toward bilateral expression (BI $>$ 50) except for Crown Pattern (um1; BI = 0), Carabelli's cusp (um2; BI = 40) and Distal Trigonid Crest (lm2; BI = 50) as shown in Table 5.

Five statistically significant $(p<0.01)$ associations between traits occurred (Table 6). The significant association between Shoveling (ui1) and Crown Pattern (um2) is not likely to be biologically meaningful given that they develop in different developmental fields (Dahlberg, 1949). The remaining four associations, however, all involved combinations of incisor and canine shoveling within and between jaws. These significant associations strongly suggest a shared developmental pathway and strong genetic component for shoveling in the anterior teeth.

\section{DISCUSSION}

My first objective was to analyze the effects of sex on trait relative frequency. Of the 13 nonmetric traits examined in this study, none displayed statistically significant sexual dimorphism. This complements the results of Alvrus (2000) who found a "fairly low degree of sexual dimorphism" in deciduous metric traits in Pima children (Alvrus, 2000:12). Together, the results of these two studies suggest that, among the Pima, sex does not strongly affect the expression of metric or nonmetric deciduous traits. Grine $(1986,1990)$ also found a lack of statistically significant sex differences for Kalahari San and South African black children. Clearly, sexual dimorphism plays little role in the development of the examined deciduous crown traits within these population samples.

My second objective was to analyze trait asymmetry. None of the deciduous variants examined were expressed significantly more often on a particular side. Only one difference between antimeres approached statistical significance (Crown Pattern [um1], $\mathrm{p}=0.054$ ), and this is likely attributable to the overall low relative frequency of this trait $(4.3 \%)$. Ten traits were expressed more often bilaterally (BI $\geq 60$ ). The overwhelming tendency toward bilateral expression is consistent with the hypothesis that strong genetic components are involved in dental trait expression (Turner et al., 1991). Crown pattern (um1) and Carabelli's cusp (um2) were expressed more often unilaterally $(B I \leq 40)$ while Distal Trigonid Crest occurred bilaterally and unilaterally equally as often $(\operatorname{lm} 2 ; \mathrm{BI}=50)$. The unilateral tendency of Crown pattern (um1) and Carabelli's cusp (um2) may be the result of their low relative frequency in the study sample $(\leq 5.1 \%)$. In sum, these data are consistent with the hypothesis that asymmetry is a random phenomenon representing environmental influences on the underlying genotype (Mayhall and Saunders, 1986; Nichol, 1990; Turner, 1985).

A fundamental assumption underlying the use of the MMD statistic is that the variables examined are not associated with one another (Sjøvold, 1973). Therefore, combining dental or skeletal nonmetric traits that are significantly associated violates the assumption of independence (Molto, 1985; Nichol, 1990). In this study, four statistically significant associations were detected 
TABLE 2. Intra-observer reliability scores for this study

\begin{tabular}{|c|c|c|c|c|c|c|c|c|}
\hline \multirow[b]{2}{*}{ Tooth } & \multirow[b]{2}{*}{ Side } & \multirow[b]{2}{*}{ Trait } & \multirow[b]{2}{*}{ Grade $^{1}$} & \multicolumn{2}{|c|}{ Per Tooth } & & \multicolumn{2}{|c|}{ Per Individual } \\
\hline & & & & $\%$ & $\mathrm{P} / \mathrm{A}^{2}$ & $\%$ & $\mathrm{P} / \mathrm{A}^{3}$ & $\%$ \\
\hline \multirow[t]{2}{*}{ ui1 } & $\mathrm{R}$ & Shovel & 15 & 75 & 19 & 95 & 20 & 100 \\
\hline & $\mathrm{L}$ & & 17 & 85 & 20 & 100 & & \\
\hline \multirow[t]{2}{*}{ ui2 } & $\mathrm{R}$ & Shovel & 15 & 75 & 15 & 75 & 20 & 100 \\
\hline & $\mathrm{L}$ & & 19 & 95 & 20 & 100 & & \\
\hline \multirow[t]{2}{*}{ uc } & $\mathrm{R}$ & Shovel & 15 & 75 & 17 & 85 & 17 & 85 \\
\hline & $\mathrm{L}$ & & 16 & 80 & 17 & 85 & & \\
\hline \multirow[t]{2}{*}{ um1 } & $\mathrm{R}$ & Crown Pattern & 17 & 85 & 20 & 100 & 20 & 100 \\
\hline & $\mathrm{L}$ & & 11 & 55 & 14 & 70 & & \\
\hline \multirow[t]{2}{*}{ um2 } & $\mathrm{R}$ & Crown Pattern & 18 & 90 & 20 & 100 & 20 & 100 \\
\hline & $\mathrm{L}$ & & 17 & 85 & 20 & 100 & & \\
\hline \multirow[t]{2}{*}{ um2 } & $\mathrm{R}$ & Carabelli's Cusp & 10 & 50 & 19 & 95 & 20 & 100 \\
\hline & $\mathrm{L}$ & & 12 & 60 & 20 & 100 & & \\
\hline \multirow[t]{2}{*}{ li1 } & $\mathrm{R}$ & Shovel & 19 & 95 & 18 & 90 & 18 & 90 \\
\hline & $\mathrm{L}$ & & 18 & 90 & 18 & 90 & & \\
\hline \multirow[t]{2}{*}{ li2 } & $\mathrm{R}$ & Shovel & 17 & 85 & 20 & 100 & 20 & 100 \\
\hline & $\mathrm{L}$ & & 15 & 75 & 20 & 100 & & \\
\hline \multirow[t]{2}{*}{ lc } & $\mathrm{R}$ & Shovel & 18 & 90 & 19 & 95 & 19 & 95 \\
\hline & $\mathrm{L}$ & & 16 & 80 & 19 & 95 & & \\
\hline \multirow[t]{2}{*}{$\operatorname{lm} 2$} & $\mathrm{R}$ & Protostylid & 5 & 25 & 10 & 50 & 13 & 65 \\
\hline & $\mathrm{L}$ & & 8 & 40 & 13 & 65 & & \\
\hline \multirow[t]{2}{*}{$\operatorname{lm} 2$} & $\mathrm{R}$ & Cusp 7 & 11 & 55 & 15 & 75 & 17 & 85 \\
\hline & $\mathrm{L}$ & & 15 & 75 & 16 & 80 & & \\
\hline \multirow[t]{2}{*}{$\operatorname{lm} 2$} & $\mathrm{R}$ & Central Ridge & 14 & 70 & 14 & 70 & 16 & 80 \\
\hline & $\mathrm{L}$ & & 15 & 75 & 14 & 70 & & \\
\hline \multirow[t]{3}{*}{$\operatorname{lm} 2$} & $\mathrm{R}$ & Distal Trigonid Crest & 17 & 85 & 19 & 95 & 20 & 100 \\
\hline & $\mathrm{L}$ & & 18 & 90 & 19 & 95 & & \\
\hline & & Total & 388 & 75 & 455 & 88 & 240 & 92 \\
\hline
\end{tabular}

${ }^{1}$ identical grade was consistently scored per tooth examined (out of 20)

${ }^{2}$ presence/absence was consistently scored per tooth examined (out of 20)

${ }^{3}$ presence/absence was consistently scored per individual examined (out of 20)

that likely have biological meaning. All involved a combination of incisor and canine shoveling. This trait was associated between ui1-ui2, ui2-uc, ui2-lc, and uc-lc. Sciulli (1998) noted:

For the total sample and in the Woodland and Pearson samples, shoveling shows strong associations between anterior teeth. The maxillary incisors are significantly associated with each other but independent of the canines, while the mandibular incisors are associated with each other, the maxillary incisors, and the mandibular canine. Shoveling of the maxillary canine is the only feature independent of shoveling in all other anterior teeth [Sciulli, 1998:196].

Clearly, shoveling in the anterior teeth is likely the result of a similar, if not identical genetic component. If this is true, the combined use of shoveling traits on different teeth in biological distance studies may adversely affect the results of the MMD statistic. Molto (1985) demonstrated that using six associated cranial variants $(p<0.015)$ in a battery of 27 significantly altered the MMD results. Nichol (1990) and Hawkey (personal communication, 2000) have found similar results using significantly associated permanent discrete traits. Molto (1985) aptly summarized:

In closing, I would like to emphasize that the concept of distance is a theoretical mathematical concept that has been borrowed and applied to population biology. Debate continues as to the meaning and/or legitimacy of distances computed using biological data (Sjøvold, 1977). In view of this, the very least researchers can do, is to obey the assumptions outlined by mathematical theory. This means that biological distances should be computed using variates that, except for an acceptable number of chance associations, are statistically independent of each other [Molto, 1985:64]. 
TABLE 3. Relative frequencies of 13 deciduous dental traits and their distribution by sex in a Pima Amerindian sample ${ }^{1-2}$

\begin{tabular}{|c|c|c|c|c|c|c|c|c|}
\hline \multirow[b]{2}{*}{ Tooth } & \multirow[b]{2}{*}{ Trait } & \multicolumn{2}{|c|}{ Total } & \multicolumn{2}{|c|}{ Males } & \multicolumn{2}{|c|}{ Females } & \multirow[b]{2}{*}{$\mathrm{P}$} \\
\hline & & $\mathrm{N}$ & $\%$ & $\mathrm{~N}$ & $\%$ & $\mathrm{~N}$ & $\%$ & \\
\hline ui1 & Shovel & 53 & 50.9 & 27 & 51.9 & 26 & 50.0 & 0.893 \\
\hline ui2 & Shovel & 73 & 71.2 & 39 & 69.2 & 34 & 73.5 & 0.686 \\
\hline $\mathrm{uc}$ & Shovel & 99 & 42.4 & 49 & 36.7 & 50 & 48.0 & 0.257 \\
\hline um1 & Crown Pattern & 94 & 4.3 & 46 & 4.3 & 48 & 4.2 & 1.000 \\
\hline um2 & Crown Pattern & 97 & 88.7 & 48 & 87.5 & 49 & 89.8 & 0.721 \\
\hline um2 & Carabelli's Cusp & 99 & 5.1 & 50 & 2.0 & 49 & 8.2 & 0.204 \\
\hline li1 & Shovel & 20 & 5.0 & 14 & 7.1 & 6 & 0.0 & 1.000 \\
\hline li2 & Shovel & 43 & 16.3 & 25 & 16.0 & 18 & 16.7 & 1.000 \\
\hline lc & Shovel & 95 & 74.7 & 47 & 76.6 & 48 & 72.9 & 0.680 \\
\hline $\operatorname{lm} 2$ & Protostylid & 99 & 80.8 & 49 & 83.7 & 50 & 78.0 & 0.474 \\
\hline $\operatorname{lm} 2$ & Cusp 7 & 96 & 70.8 & 49 & 77.6 & 47 & 63.8 & 0.139 \\
\hline $\operatorname{lm} 2$ & Central Ridge & 94 & 70.2 & 47 & 72.3 & 47 & 68.1 & 0.652 \\
\hline $\operatorname{lm} 2$ & Distal Trigonid Crest & 97 & 28.9 & 48 & 35.4 & 49 & 22.4 & 0.159 \\
\hline
\end{tabular}

${ }^{1} \mathrm{~N}$, \# of individuals; \%, relative frequency.

${ }^{2} \mathrm{P}$, significance level (Chi-square or Fisher's exact test).

Therefore, researchers should be extremely cautious when using a number of deciduous shoveling traits in biological distance analyses. The use of "key" teeth for deciduous variants, as is common practice in permanent discrete trait studies (Hawkey, 1998), is recommended.

\section{CONCLUSIONS}

The nonmetric traits of the deciduous dentition examined herein showed no statistically significant sex or side differences in trait relative frequency. The majority of the traits were expressed bilaterally. Together these data suggest the deciduous traits examined are primarily under genetic control with negligible environmental influences involved in their expression. Four statistically significant associations between shoveling traits on the anterior teeth were interpreted as representing a shared developmental pathway and genetic component. Therefore, using more than one deciduous shoveling trait as part of a trait battery measuring biological distance would violate the mathematical assumption of independence between variables. In sum, the observed lack of significant sexual dimorphism and asymmetry in this study supports the use of deciduous discrete traits

TABLE 4. Relative frequencies of 13 deciduous dental traits and their distribution by antimere in a Pima Amerindian sample s-2 $^{1-2}$

\begin{tabular}{|c|c|c|c|c|c|c|c|c|}
\hline \multirow[b]{2}{*}{ Tooth } & \multirow[b]{2}{*}{ Trait } & \multicolumn{2}{|c|}{ Total } & \multicolumn{2}{|c|}{ Right } & \multicolumn{2}{|c|}{ Left } & \multirow[b]{2}{*}{$\mathrm{P}$} \\
\hline & & $\mathrm{N}$ & $\%$ & $2 \mathrm{~N}$ & $\%$ & $2 \mathrm{~N}$ & $\%$ & \\
\hline ui1 & Shovel & 53 & 50.9 & 53 & 50.9 & 50 & 44.0 & 0.481 \\
\hline ui2 & Shovel & 73 & 71.2 & 66 & 68.2 & 71 & 70.4 & 0.776 \\
\hline uc & Shovel & 99 & 42.4 & 94 & 36.2 & 97 & 40.2 & 0.566 \\
\hline um1 & Crown Pattern & 94 & 4.3 & 86 & 4.7 & 91 & 0.0 & 0.054 \\
\hline um2 & Crown Pattern & 97 & 88.7 & 94 & 83.0 & 95 & 88.4 & 0.285 \\
\hline um2 & Carabelli's Cusp & 99 & 5.1 & 99 & 3.0 & 96 & 4.2 & 0.718 \\
\hline li1 & Shovel & 20 & 5.0 & 18 & 5.6 & 18 & 5.6 & 1.000 \\
\hline li2 & Shovel & 43 & 16.3 & 38 & 13.2 & 39 & 12.8 & 1.000 \\
\hline lc & Shovel & 95 & 74.7 & 89 & 73.0 & 93 & 66.7 & 0.350 \\
\hline $\operatorname{lm} 2$ & Protostylid & 99 & 80.8 & 96 & 74.0 & 98 & 74.5 & 0.933 \\
\hline $\operatorname{lm} 2$ & Cusp 7 & 96 & 70.8 & 91 & 65.9 & 94 & 61.7 & 0.549 \\
\hline $\operatorname{lm} 2$ & Central Ridge & 94 & 70.2 & 89 & 62.9 & 91 & 64.8 & 0.789 \\
\hline $\operatorname{lm} 2$ & Distal Trigonid Crest & 97 & 28.9 & 94 & 19.1 & 94 & 24.5 & 0.377 \\
\hline
\end{tabular}

${ }^{1} 2 \mathrm{~N}$, \# of sides; \%, relative frequency.

${ }^{2} \mathrm{P}$, significance level (Chi-square or Fisher's exact test). 
TABLE 5. The symmetrical tendencies of 13 deciduous dental traits used in this study

\begin{tabular}{clcccc}
\hline \multirow{2}{*}{ Tooth } & & \multicolumn{2}{c}{ Trait Presence } & Index of & Symmetrical \\
& Trait & Bilateral & Unilateral & Bilaterality & Tendency \\
\hline ui1 & Shovel & 22 & 3 & 88.0 & bilateral \\
ui2 & Shovel & 43 & 4 & 91.5 & bilateral \\
uc & Shovel & 31 & 7 & 81.6 & bilateral \\
um1 & Crown Pattern & 0 & 2 & 0.0 & unilateral \\
um2 & Crown Pattern & 76 & 6 & 92.7 & bilateral \\
& Carabelli's Cusp & 2 & 3 & 40.0 & unilateral \\
li1 & Shovel & 1 & 0 & 100.0 & bilateral \\
li2 & Shovel & 3 & 2 & 60.0 & bilateral \\
lc & Shovel & 56 & 8 & 87.5 & bilateral \\
lm2 & Protostylid & 64 & 12 & 84.2 & bilateral \\
& Cusp 7 & 50 & 14 & 78.1 & bilateral \\
& Central Ridge & 49 & 10 & 83.1 & bilateral \\
& Distal Trigonid Crest & 13 & 13 & 50.0 & --- \\
\hline
\end{tabular}

in population analyses if the necessary precautions are taken involving significant associations between variants.

\section{LITERATURE CITED}

Alvrus A. 2000. Sex dimorphism in the deciduous dentition of modern Pima. Dental Anthropology 14:9-13.

Bailey-Schmidt. 1995. Population distribution of the tuberculum dentale complex and anomalies of the maxillary anterior teeth. M.A. thesis, Arizona State University, Tempe.

Baume RM, Crawford MH. 1980. Discrete dental trait asymmetry in Mexican and Belize groups. Am J Phys Anthropol 52:315-321.

Biggerstaff RH. 1973. Heritability of the Carabelli cusp in twins. J Dent Res 52:40-44.

Dahlberg AA. 1949. The dentition of the American Indian. In: WS Laughlin WS, editor. The physical anthropology of the American Indian. New York: Viking Fund, p 138-176.

Daly M, Wilson M. 1983. Sex, evolution, and behaviour, 2nd ed. Belmont, CA: PWS Publishers.

Dempsey PJ, Townsend GC, Richards LC. 1999. Increased tooth crown size in females with twin brothers: Evidence for hormonal diffusion between human twins in utero. Am J Hum Bio 11:577-586.

Fairgrieve SI, Molto JE. 2000. Cribra orbitalia in two temporally disjunct population samples from the Dakhleh Oasis, Egypt. Am J Phys Anthropol 111: 319-331.

Garn SM, Cole PE, Smith BH. 1979. The effect of sample size on crown side asymmetry. J Dent Res 58:2012.

Goldstein MS. 1948. Dentition of Indian crania from Texas. Am J Phys Anthropol 6:63-84.

Grine FE. 1986. Anthropological aspects of the deciduous teeth of South African blacks. In: Singer R, Lundy JK, editors. Variation, culture and evolution in
African populations. Johannesburg: Witwatersrand University Press, p 47-83.

Grine FE. 1990. Deciduous dental features of Kalahari San: comparison of non-metrical traits. In: Sperber $\mathrm{GH}$, editor. Apes to angels: essays in anthropology in honor of Philip V. Tobias. New York: Wiley-Liss, p 153-169.

Hanihara K. 1956. Studies on the deciduous dentition of the Japanese and the Japanese-American hybrids. III Deciduous lower molars. J Anthropol Soc Nippon 64:95.

Hanihara K. 1961. Criteria for classification of crown characters of the human deciduous dentition. J Anthrop Soc Nippon 64:27-45.

Hanihara K. 1963. Crown characters of the deciduous dentition of the Japanese-American hybrids. In: Brothwell DR, editor. Dental anthropology. London: Pergamon Press, p 104-124.

Hanihara K. 1965. Some crown characters of the deciduous incisors and canines in JapaneseAmerican hybrids. J Anthrop Soc Nippon 72:135145.

Hanihara K. 1970. Mongoloid dental complex in the deciduous dentition with special reference to the dentition of the Ainu. J Anthrop Soc Nippon 78:3-17.

Harris EF. 1977. Anthropologic and Genetic Aspects of the Dental Morphology of Solomon Islanders, Melanasia. Ph.D. dissertation, Arizona State University, Tempe.

Harris EF. 1980. Sex differences in lingual marginal ridging on the human maxillary central incisor. Am J Phys Anthropol 52:541-548.

Hawkey DE. 1998. Out of Asia: Dental evidence for affinities and microevolution of early populations from India/Sri Lanka. Ph.D. dissertation, Arizona State University, Tempe.

Hrdlicka A. 1920. Shovel-shaped teeth. Am J Phys An- 
TABLE 6. Associations between the 13 deciduous dental traits used in this study $y^{1-3}$

\begin{tabular}{lllllllllllllll}
\hline & Tooth & ui1 & ui2 & uc & um1 & um2 & um2 & li1 & li2 & lc & lm2 & lm2 & lm2 & lm2 \\
Tooth & Trait & SH & SH & SH & CP & CP & CC & SH & SH & SH & PR & C7 & CR & DTC \\
\hline ui1 & SH & - & $\mathbf{0 . 3 6}$ & 0.17 & -0.21 & $\mathbf{0 . 3 9}$ & 0.00 & - & -0.05 & 0.04 & 0.16 & 0.19 & 0.31 & -0.06 \\
ui2 & SH & $\mathbf{0 . 0 1}$ & - & $\mathbf{0 . 4 1}$ & 0.16 & 0.31 & 0.02 & - & 0.14 & $\mathbf{0 . 4 2}$ & -0.04 & 0.28 & 0.03 & -0.10 \\
uc & SH & 0.21 & $\mathbf{0 . 0 0}$ & - & -0.07 & 0.04 & 0.17 & 0.25 & 0.26 & $\mathbf{0 . 2 8}$ & -0.05 & 0.08 & 0.13 & -0.09 \\
um1 & CP & 0.23 & 0.31 & 0.64 & - & 0.08 & -0.05 & - & 0.20 & 0.13 & -0.02 & -0.15 & -0.02 & 0.03 \\
um2 & CP & $\mathbf{0 . 0 1}$ & 0.02 & 0.76 & 1.00 & - & 0.08 & 0.12 & 0.19 & 0.24 & -0.09 & -0.09 & 0.05 & -0.13 \\
um2 & CC & 1.00 & 1.00 & 0.16 & 1.00 & 1.00 & - & - & -0.10 & -0.09 & -0.12 & -0.06 & 0.16 & -0.15 \\
li1 & SH & - & - & 0.45 & - & 1.00 & - & - & 1.00 & -0.40 & 0.13 & 0.10 & -0.39 & -0.14 \\
$\operatorname{li2}$ & SH & 1.00 & 0.64 & 0.11 & 0.32 & 0.57 & 1.00 & 0.05 & - & 0.09 & -0.04 & 0.12 & -0.14 & 0.00 \\
lc & SH & 0.79 & $\mathbf{0 . 0 0}$ & $\mathbf{0 . 0 1}$ & 0.57 & 0.03 & 0.59 & 0.25 & 1.00 & - & 0.13 & -0.03 & -0.06 & 0.11 \\
$\operatorname{lm} 2$ & PR & 0.29 & 1.00 & 0.66 & 1.00 & 0.68 & 0.25 & 1.00 & 1.00 & 0.24 & - & 0.16 & -0.03 & -0.03 \\
$\operatorname{lm} 2$ & C7 & 0.18 & 0.02 & 0.42 & 0.21 & 0.50 & 0.62 & 1.00 & 0.65 & 0.78 & 0.12 & - & 0.23 & 0.05 \\
$\operatorname{lm} 2$ & CR & 0.02 & 0.81 & 0.21 & 1.00 & 0.73 & 0.32 & 0.26 & 0.39 & 0.61 & 0.81 & 0.02 & - & 0.05 \\
$\operatorname{lm} 2$ & DTC & 0.68 & 0.42 & 0.37 & 1.00 & 0.29 & 0.32 & 1.00 & 1.00 & 0.29 & 0.80 & 0.63 & 0.60 & - \\
\hline
\end{tabular}

${ }^{1} \mathrm{SH}$, shovel; $\mathrm{CP}$, crown pattern; CC, Carabelli's cusp; PR, protostylid; C7, cusp 7; CR, central ridge; DTC, distal trigonid crest.

${ }^{2}$ phi coefficients are above the main diagonal; $p$ values are below the main diagonal.

${ }^{3}$ bolded values are statistically significant at the 0.01 level.

thropol 3:429-465.

Johnse HG. 1947. The primary dentition in Homo sapiens and the search for primitive features. Am J Phys Anthropol 5:251-274.

Jorgensen K. 1956. The deciduous dentition: a descriptive and comparative anatomical study. Acta Odontol Scand 14:1-202.

Kitagawa Y. 2000. Nonmetric morphological characters of deciduous teeth in Japan: Diachronic evidence of the past 4000 years. Int J Osteoarch 10:242-253.

Lukacs JR, and Walimbe SR. 1984. Deciduous dental morphology and the biological affinities of a late Chalcolithic skeletal series from western India. Am J Phys Anthropol 65:23-30.

Mange AP, Mange EJ. 1990. Genetics: Human aspects. 2nd edition. Sunderland, MA: Sinauer Associates.

Mayhall JT. 1992. Techniques for the study of dental morphology. In: Saunders SR, Katzenberg MA, editors. Skeletal biology of past peoples: research methods. New York: Wiley-Liss, Inc, p 59-78.

Mayhall JT, Saunders SR. 1986. Dimensional and discrete dental trait asymmetry relationships. Am J Phys Anthropol 69:403-411.

Meredith HV, Hixon EH. 1954. Frequency, size, and bilateralism of Carabelli's tubercle. J Dent Res 33: 435-440.

Molto JE. 1979. The assessment and meaning of intraobserver error in population studies based on discontinuous cranial traits. Am J Phys Anthropol 51:333-344.

Molto JE. 1983. Biological relationships of southern Ontario Woodland Peoples: The evidence of discontinuous cranial morphology. National Museums of
Canada: Ottawa.

Molto JE. 1985. Simultaneous occurrence of discontinuous cranial traits: Some theoretical and practical considerations for population analyses. Can Rev Phys Anthropol 4:57-65.

Nichol CR. 1990. Dental genetics and biological relationships of the Pima Indians of Arizona. Ph.D. dissertation, Arizona State University, Tempe.

Nichol CR, Turner II CG. 1986. Intra- and interobserver concordance in classifying dental morphology. Am J Phys Anthropol 69:299-315.

Ossenberg NS. 1976. Within and between race distances in population studies based on discrete traits of the human skull. Am J Phys Anthropol 45:701-716.

Sciulli PW. 1977. A descriptive and comparative study of the deciduous dentition of prehistoric Ohio Valley Amerindians. Am J Phys Anthropol 47:71-80.

Sciulli PW. 1990. Deciduous dentition of a Late Archaic population of Ohio. Hum Biol 62:221-245.

Sciulli PW. 1998. Evolution of the dentition in prehistoric Ohio Valley Native Americans: II. Morphology of the deciduous dentition. Am J Phys Anthropol 106:189-205.

Scott GR. 1977. Classification, sex dimorphism, association, and population variation of canine distal accessory ridge. Hum Biol 49:453-469.

Scott GR. 1980. Population variation of Carabelli's trait. Hum Biol 52:63-78.

Scott GR, Turner II CG. 1997. The anthropology of modern human teeth: Dental morphology and its variation in recent human populations. New York: Cambridge University Press.

Sjøvold T. 1973. The occurrence of minor non-metri- 
cal variants in the skeleton and their quantitative treatment for populations comparisons. Homo 24: 204-233.

Sjøvold T. 1977. Non-metrical divergence between skeletal populations: the theoretical foundation and biological importance of C.A.B. Smith's Mean Measure of Divergence. Ossa Vol. 4 (supplement 1).

Smith BH, Garn SM, Cole PE. 1982. Problems of sampling and inference in the study of fluctuating dental asymmetry. Am J Phys Anthropol 58:281-289.

Smith P. 1976. Evolutionary changes in the deciduous dentition of Near Eastern populations. Bull Group Int Rech Sci Stomatol 19:187-198.

Smith P. 1978. Evolutionary changes in the deciduous dentition of Near East populations. J Hum Evol 7: 401-408.

Tocheri MW, Molto JE. In press. Aging fetal and juvenile skeletons from Roman period Egypt using basiocciput osteometrics. Int J Osteoarch.

Townsend GC. 1981. Fluctuating asymmetry in the deciduous dentition of Australian Aboriginals. J Dent Res 60:1849-1857.

Townsend GC, Brown T. 1980. Dental asymmetry in Australian Aboriginals. Hum Biol 52:661-673.

Townsend GC, Brown T. 1981. The Carabelli trait in Australian Aboriginal dentition. Arch Oral Biol 26: 809-814.

Trinkaus E. 1978. Bilateral asymmetry of human skeletal nonmetric traits. Am J Phys Anthropol 49:315-318.

Turner II CG. 1985. Expression count: a method for calculating morphological dental trait frequencies by using adjustable weighting coefficients with standard ranked scales. Am J Phys Anthropol 68: 263-267.

Turner II CG, Scott GR. 1977. Dentition of Easter Islanders. In: Dahlberg AA, Graber TM, editors. Orofacial growth and development. The Hague: Mouton, $\mathrm{p}$ 229-249.

Turner II CG, Nichol CR, Scott GR. 1991. Scoring procedures for key morphological traits of the permanent dentition: The Arizona State University dental anthropology system. In: MA Kelley, CS Larsen, editors. Advances in dental anthropology. New York: Wiley-Liss, p 13-32.

\section{Skeletal Anthropology Program}

\section{Opening January 2003}

Department of Anthropological Sciences

Universidad Autónoma de Yucatán, Mérida

The Department of Anthropological Sciences of the Universidad Autónoma de Yucatán, Mérida, offers a new Program in Skeletal Anthropology leading to a certificate or forming part of a M.S. in Anthropological Sciences. The program is oriented to graduate students, professors and other professionals interested in bioarchaeology (archaeology, physical anthropology, forensic sciences, and biology).

The program offers a firm background in the theory, methodology, fieldwork and laboratory research. It is designed to train qualified professionals and broaden their range of job opportunities, or open the door for students towards doctorate programs in anthropology.

\section{The Program}

The program encompasses three quarters. The curriculum revolves around theory, methodology and practical applications. Along with the department facilities, the program will benefit from a specialized lab and on-going research projects based on several skeletal collections of the region. The lab is fully equipped for up-to-date bone histomorphology in addition to standard osteological and dental analyses. Primary faculty are Dr. Vera Tiesler and Dr. Andrea Cucina

\section{Admission}

Applicants must apply directly to the Department. In addition to general graduate admission requirements of the UADY, applicants must:

- Hold a B.A. or B.S. degree with a major in anthropolgy, social, biological or medical sciences.

- Have obtained a minimum GPA of 3.0 or equivalent.

- Have competence in reading, writing and speaking Spanish.

- A letter of intent showing a clear study goal.

The Department will evaluate applications received by October 30, 2002. Courses will begin January of 2003.

\section{More information:}

Secretaria Académica

Facultad de Ciencias Antropológicas/UADY Tel. 99-25-45-23

or write to Dr. V. Tiesier at vtiesler@yahoo.com http:www.uady.mx/sitios/antropol/index.html

Information supplied by Dr. Andrea Cucina 